\title{
A Review and Roadmap of Online Learning Platforms and Tutorials in Digital Archaeology
}

\author{
Dries Daems @
}

\section{OVERVIEW}

With an ever-growing range of computational tools and applications now available for archaeological practice, the potential of digital archaeology is greater than ever before. Yet, archaeological curricula have not always followed suit, and many archaeologists are not up-todate with the necessary digital skills. To fill this gap, online tutorials and learning platforms are being developed to familiarize archaeologists and students with the potential of digital media for archaeological research practices. Given the essential pedagogical role of these platforms, their quality is deserving of deeper interrogation. Here, I review three major platforms offering tutorials on digital archaeology: the Programming Historian, Project MERCURY-SIMREC, and the Open Digital Archaeology Textbook. These are evaluated and compared based on their goals, design (intuitiveness, ease of use), accessibility (use of jargon, required prerequisite knowledge, software requirements), scope (target audience, range of skills addressed, targeted level of improvement), and efficiency (whether or not they achieve their intended goals). The review concludes with a road map contextualizing the current state of available resources in light of the wider state of digital archaeology, and it considers pathways toward future development.

Keywords: digital archaeology, tutorials, online learning, digital resources

\section{DIGITAL LEARNING RESOURCES IN ARCHAEOLOGY}

\begin{abstract}
Digital media are increasingly important in the field of archaeology. This escalating importance can, in part, be explained by an evergrowing range of tools and applications becoming available as computing power increases and standard packages for statistical analyses and modeling practices are developed. However, the means by which we critically use and assess the impact of digital archaeology's methods and resources have not yet fully found their way into the archaeological curricula. Although individual courses can be added to address new techniques and tools, due to institutional inertia, the curriculum as a whole often cannot keep up with the rapid developments in the field, and few programs exist that offer a holistic approach to digital archaeology.
\end{abstract}

In the absence of official digital archaeological educational models, a number of grassroots initiatives have sprouted in recent years to fill the gap. These initiatives take many forms and address a range of niches in the digital archaeology landscape, including not only the educational resources discussed below but also model repositories such as OpenABM by the CoMSES Network (2019), online data archives such as tDAR by Digital Antiquity (2019), compendia of digital tools such as the Digital Archaeology Knowledge Base (Institute for Digital Archaeology Method \& Practice Knowledge Base 2019), and grassroots initiatives such as bibliographic lists on topics in digital archaeology (Romanowska and Linde 2017).
Each of these resources provides interested parties with necessary background information, methods to test, data with which to play, and examples from which to learn. It is against this background that the educational resources discussed here have emerged. Given the available options, archaeologists and students looking for the most suitable environment to hone their skills now need to make considered decisions about which approaches best suit their needs. Because the availability of open educational resources (which sit outside of formal curricula) markedly lowers the threshold for participation, one might worry about the lack of official mechanisms for assessing and controlling their quality. The goal of my review, therefore, is to compare and evaluate three online learning environments: the Open Digital Archaeology Textbook (ODATE), ${ }^{1}$ Project MERCURY-SIMREC (PM), ${ }^{2}$ and the Programming Historian $(\mathrm{PH}){ }^{3}$

These environments are particularly worthy of attention because they represent different approaches to learning. Specifically, ODATE aims to provide a wide-reaching, integrated overview of digital archaeology, covering specific methods and techniques as well as the embedding of these tools in an integrated digital workflow. $\mathrm{PH}$, in turn, provides a set of individual, unconnected tutorials addressing a range of distinct tools and techniques to facilitate digital research and teaching. Finally, PM offers a more focused approach to a specific topic in digital archaeologycomputational modeling. Table 1 offers a more detailed overview of each of their offerings. Below, I present my evaluation strategy and, from there, I apply it to the three learning environments. I conclude with a short roadmap for the future, contextualizing 
TABLE 1. Summary of the Evaluation of the Open Digital Archaeology Textbook (ODATE), Project MERCURY-SIMREC (PM), and the Programming Historian (PH).

\begin{tabular}{|c|c|c|c|c|}
\hline Traits & Parameters & ODATE & Project MERCURY-SIMREC & $\begin{array}{l}\text { Programming } \\
\text { Historian }\end{array}$ \\
\hline \multirow[t]{3}{*}{ Scope } & Target audience & $\begin{array}{l}\text { Second-third-year archaeology } \\
\text { students }\end{array}$ & Scholars in Roman studies & Digital historians \\
\hline & Range of skills & Broad & Focused & Very broad \\
\hline & $\begin{array}{l}\text { Targeted } \\
\text { improvement }^{\mathrm{a}}\end{array}$ & Low & Low & Low \\
\hline \multirow[t]{4}{*}{ Accessibility } & Language & English & English & $\begin{array}{l}\text { English, Spanish, } \\
\text { French }\end{array}$ \\
\hline & $\begin{array}{l}\text { Software } \\
\text { requirements }\end{array}$ & None & Open-source software & Open-source software \\
\hline & Entrance level & $\begin{array}{l}\text { First-year introductory course to } \\
\text { archaeology }\end{array}$ & Different career stages & Nonspecialists \\
\hline & Use of jargon & Low & Low & Low \\
\hline Goals $^{b}$ & Content & Textbook, tutorials & $\begin{array}{l}\text { Tutorials, datasets, model library, } \\
\text { bibliography }\end{array}$ & Tutorials \\
\hline \multirow[t]{2}{*}{ Design } & Intuitiveness & High & High & Medium \\
\hline & Ease of use & High & High & High \\
\hline Efficiency $^{c}$ & Targets reached & High & High & High \\
\hline
\end{tabular}

a"Targeted improvement" refers to the amount of skill and expertise built up through each of the educational tools offered by these three resources. Most of the provided courses offer well-defined introductions to specific tools or skills, and they aim for a small increase in expertise (for example, from no background knowledge to beginner, or from beginner to intermediate).

b"Goals" refer to educational items offered by the resources, expressing the ways they want to offer educational support.

"Efficiency" refers to the degree to which the individual courses succeed in the aims they set out at the start. In relation to efficiency, "targets reached" refers to the accomplishment of these aims.

these resources in light of the wider state of digital archaeology and considering pathways toward its future development.

\section{EVALUATION METHODOLOGY}

To assess ODATE, PM, and PH, I have focused on analyzing their quality and effectiveness critically. To do this, I compared their goals (content), design (intuitiveness, ease of use), accessibility (use of jargon, required prerequisite knowledge, software requirements), scope (target audience, range of skills addressed, targeted level of improvement), and efficiency (whether or not they achieve their intended goals). My focus on these parameters aims to provide a broad-brush overview of key features of these resources. I derive my evaluation from studying a combination of stated qualifications and criteria gathered from the project websites and from personal testing of the offered resources. Such testing entailed following one or more courses and tutorials from each of these resources. A summary of this evaluation, divided into five traits and 11 parameters for each of the three resources, can be found in Table 1.

\section{PRESENTING AND EVALUATING THE RESOURCES}

All three learning environments offer open-access tutorials. ODATE also offers an extensive textbook on digital archaeology, whereas PM provides datasets, a model library, and a bibliography on computational modeling in Roman archaeology. The home pages of all three websites offer a comprehensive and intuitive overview of what can be expected, which is easily navigable. Only the lesson index of $\mathrm{PH}$ requires a closer look due to the larger number of options to filter searches, including associated labels such as "topic" and "phase in the research process." It also allows sorting by publication date and difficulty (Figure 1). The high number of lessons (79) available on PH might cause some initial confusion, but once the user becomes familiar with the options, the interface offers a fairly intuitive means of exploring lesson subjects.

These projects are, to a large extent, community efforts, given that they are open to contributions from wider groups of archaeologists and students or interested volunteers. PM allows people to send suggestions to update its available archive of models and open datasets, and it curates its open-access bibliography through the reference manager software Zotero. Similarly, PH invites volunteers to send in new tutorials on digital methods. ODATE goes one step further and offers its text in a "perpetual beta" format, inviting the community to contribute corrections, additions, or deletions. The commitment to open science is expressed in minimal software requirements, with $\mathrm{PM}$ and $\mathrm{PH}$ mainly providing tutorials using open-source software such as NetLogo (agent-based modeling), R (data analysis, network science), Python (data analysis and visualization), and Neo4j (database management and analysis). ODATE again goes further with online repositories of text and computer code using Binder (an open-source web application for managing digital repositories) to launch Jupyter Notebook environments (open-source software for 


\section{Lesson Index}

Our lessons are organized by typical phases of the research process, as well as general topics. Use the buttons to filter lessons by category. If you can't find a skill, technology, or tool you're looking for, please let us know!

\begin{tabular}{|l|l|l|}
\hline ACQUIRE (12) TRANSFORM (30) ANALYZE (17) PRESENT (19) SUSTAIN (2) \\
\hline
\end{tabular}

\begin{tabular}{|c|c|c|c|c|c|}
\hline APIS (6) & HON (20) & DATA MANA & EMENT (6) & TA MANIPULATION (21) & DISTANT READING (11) \\
\hline SET UP (7) & LINKED O & DEN DATA (1) & MAPPING (11) & NETWORK ANALYSIS (5) & WEB SCRAPING (6) \\
\hline
\end{tabular}

RESET TO SEE ALL LESSONS (80)

SORT BY PUBLICATION DATE ^

SORT BY DIFFICULTY $\nabla$

FIGURE 1. Filters and sorting options provided in the lesson index of $\mathrm{PH}$.

interactive computing) that allow students to complete the various tutorials through their web browser. This functionality altogether eliminates the need for participants to install software on their own machines.

When looking at the lessons themselves, some clear differences emerge. While English is the main language for ODATE and PM, $\mathrm{PH}$ also offers 44 lessons in Spanish and five in French (Figure 2). Expected prerequisite knowledge is defined quite clearly: ODATE states that at least a first-year introductory course to archaeology is needed, aiming mainly at second- and third-year archaeology students via its concern for data analysis, databases, and spatial archaeology (Figure 3). At the same time, more advanced topics such as web scraping, working with APIs (application programming interfaces), and even sonification (mapping time series data to musical notation) are offered as well, which seem to transcend the level of the average archaeology student. PM explicitly states that students from different career stages can benefit from its resources, although the lessons are particularly aimed at scholars in Roman studies (e.g., simulating Roman transport systems and exchange networks; Figure 4). Finally, $\mathrm{PH}$ focuses on providing learning tools for the most general audience, stating that all its lessons should be understandable to nonspecialists but that they are aimed generally at digital historians. Although not all the lessons offered by $\mathrm{PH}$ are suitable for beginners (e.g., courses such as Temporal Network Analysis, which require prior knowledge of network visualization and analysis and data analysis with $\mathrm{R})$, the option to sort lessons by difficulty makes it very easy for students to pick ones that match their background level. As a result, the use of jargon is generally limited and course appropriate.

Clear differences can also be observed in the range of skills addressed by the three resources. PM focuses strongly on coding skills related particularly to agent-based modeling and network analysis. The other two, by contrast, address a wider range. ODATE offers tutorials on Jupyter Notebooks, GitHub, APIs, data science, database management, linked open data, spatial analysis, data scraping, LiDAR, agent-based modeling, Tensorflow (an open-source software library for dataflow and differentiable programming), and visual analysis. $\mathrm{PH}$ includes lessons on $\mathrm{API}$, natural language processing, gravity modeling, machine learning, audiovisual analysis, time series analysis, geospatial mapping, data visualization, database management, data analysis, text parsing, web mapping, linked open data, text processing, GitHub, website development, corpus analysis, data mining, georeferencing, and topic modeling. In sum, both ODATE and PH combine tutorials on the absolute basics (such as using GitHub and database management) while also offering a host of in-depth tutorials addressing specialized skills. $\mathrm{PH}$ addresses a wider range of topics, which is likely the result of its longer history and larger project team.

The targeted improvement (meaning educational progress from one level to the next) for all tutorials is fairly low, aiming first and foremost at providing an introduction to various topics or addressing the honing of a specific skill or task. No in-depth learning curve is articulated or followed in these resources, nor are individual lessons necessarily incorporated into a broader narrative or course that ties the strands of expertise together. The only partial exception is ODATE's textbook, which offers a more general introduction on digital archaeology along with its tutorials. Progress in the textbook, however, does not necessarily match the progress in skills set out in the tutorials.

The question of whether these resources are efficient, in the sense that the intended targets are reached, is difficult to answer and will always depend on the individual student. Most tutorials, however, can be completed in a fairly limited amount of time (within the range of one to three hours), which gives the student sufficient incentive to finish a lesson in a single go or in a limited number of sessions. On PH, several lessons indicate average/expected duration.

Finally, in terms of evaluation of the resources, no open forum for commenting on the tutorials is available. All three resources, however, provide clear instructions on how to contact the team to suggest changes. Special mention must be given to the 


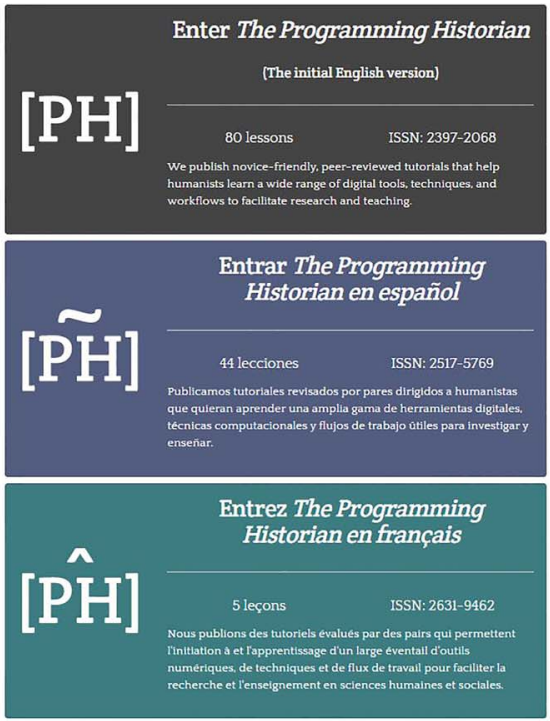

FIGURE 2. The Programming Historian home page.

"perpetual beta" status of ODATE, which means that the Digital Archaeology Textbook that accompanies the tutorials is a living document: all users can see the highlights and annotations of other users, such as where they had difficulties or were particularly inspired. This is perhaps the most innovative approach to date to get a wider community of users involved in a collective learning process. Unfortunately, at the time of writing (November 2019), no lively community has yet emerged, but one can hope that it might still develop as time goes on and a wider audience is reached. All three resources also provide easily discoverable links on their main web page to outline their contact details.

\section{SUMMARY OF CONCLUSIONS}

In sum, all three resources reviewed here offer introductions to various themes or address specific skills, rather than providing in-depth coverage of topics-but what they lack in depth, they make up for in range and coverage. Although the entrance level and target audience are clearly defined, the comprehensive nature of the skills and knowledge offered ensures that all three resources have plenty to offer to archaeologists, historians, or other scholars interested in using computational methods and tools for studying the past.

PM is clearly the most specific medium, with a more restricted range of skills and audience than the others. But this strong focus makes it a valuable resource for a specialized community with a specific interest in digital tools and methodologies. ODATE stands out for its combination of tutorials and textbook, as well as for its usage of Binder to set up online repositories with no software requirements. This combination results in a unique approach to education in digital archaeology that is clearly different from other resources and that appears promising for the future. $\mathrm{PH}$ can profit from the advantage of increasing returns on scale associated with its bigger size compared to the others, expressed in the greater number, scope, and language accessibility of lessons offered. It also allows lessons to be peer-reviewed-albeit by volunteers - which provides an additional mark of quality as an educational resource. All editors and reviewers are named and acknowledged at the beginning of each tutorial.

\section{A ROADMAP FOR THE FUTURE OF DIGITAL ARCHAEOLOGY}

One of the questions I have asked above is whether these resources are effective. In a sense, they clearly are. They provide an introduction to various themes, familiarizing scholars and students with topics and skills relevant to the field. In another sense, however, they are not. Digital archaeology is more than a set of skills that can be gained in a "checkbox" fashion. Not only does it include a wide range of quantitative and qualitative tools, statistical approaches, applied computational technologies, and software development, but it links to larger cultural trends toward sharing, collaboration, openness, and interconnectivity (Perry and Taylor 2018).

All three learning environments clearly support the principles of open science and operate accordingly by focusing on open access and using open-source resources. They still, however, mainly privilege the technical aspects of results-driven and skills-oriented applications rather than critical evaluation of wider intellectual ramifications and impact. Even though digital archaeology, by this point, has a relatively long pedigree, it is still mostly left at the fringes of the archaeological discipline. Yet, it has been rightfully stated that "by doing archaeology digitally it should seek . . . to make a difference to the broader epistemic and pragmatic contexts of archaeological work" (Dallas 2015:178). For digital archaeology to move toward the very core of the archaeological discipline, focus needs to shift from applications and methods to theories and epistemologies (Perry and Taylor 2018). 


\section{Getting Started with ODATE}

Graham, Gupta, Smith, Angourakis, Carter, \& Compton

\section{Getting Started with ODATE}

Thank you for your interest in ODATE!

Some of its features:

- Responsive design - view it on mobile

- computational environments using Jupyter + Binder

- Remixable text

- Collaborative writing process

- Collaborative reading

We wrote this text with a particular kind of student in mind. We imagined this student as having already taken a first year introductory course to archaeology of the kind that surveys the field, its history, and its principle methods and theoretical positions. Very few courses of that kind can include any depth in digital methods and theory, which is understandable when we look at the incredible variety of archaeological work, skills, and interests! Digital work is every bit as diverse as other kinds of archaeology, but it also presents its own particular challenges. One of these is the anxiety that comes when one first approaches the computer for anything more complex than word processing or a bit of social media. 'What happens if I break it?'; 'I'm not techy!'; 'If I wanted to do computers, I wouldn't have gone into this!' are all actual student concerns that we have heard in our various classrooms.

It'll be ok.

We take a pedagogical perspective that focuses on the learning that happens when we make things, when we experiment or otherwise play around with materials and computing, and especially, when/if things break. It's a perspective that finds value in 'failing gloriously', in trying to push ourselves beyond our comfort level. The only thing that you will need therefore to be successful in learning some of the basic issues around digital archaeology is a willingness to consider why things didn't work the way they ought to have, and a web browser. We built this textbook with its very own digital archaeology computer built right in! There's nothing you can break on your own machine, nor does your machine have to be very powerful.
This supporting website explains how to write for ODATE, use ODATE with your class, and other technical pieces that will enhance your use of ODATE.

Read the textbook.

Run code in a notebook

FIGURE 3. ODATE home page.

The resources reviewed here clearly offer a first step in the right direction by aiming to reach a wide audience-outside of official curricula-and by familiarizing people with the skills and tools of digital archaeology. Whereas PH only offers straightforward tutorials, PM and ODATE try to capture this bigger picture to some degree. PM includes an extensive section on "Why Model?" that provides a basic introduction to the necessities and potential of modeling approaches in archaeology, combining comprehensive texts, archaeological examples, and intuitive visual interfaces. ODATE goes one step further, providing an accompanying textbook on digital archaeology — but the project still needs to take additional steps if it is to reach its objectives of providing a pedagogical perspective on digital archaeology that goes beyond specific skills to focus on digital learning.

Ultimately, the way forward for digital archaeology will be driven by a combination of the increasing availability of digital resources and a renewed focus on the wider epistemological ramifications of doing digital archaeology, as well as changing mentalities in educational practices. These changing mentalities must explicitly involve a focus on extended learning trajectories that go beyond the cut-and-paste application of individual techniques and move toward developing digitally informed habits of thought. Once we succeed in making this transition, digital 
About $\checkmark \quad$ Why model? Datasets Model Library Tutorials Bibliography Case Studies $\checkmark \quad$ Boardgame

8TH APRIL 2018

\section{Welcome to Project MERCURY-SIMREC}

Project MERCURY-SIMREC develops and shares resources to encourage the use of computational modelling in Roman economy studies. It provides:

- a playable explanation of why we should model,

- practical tutorials,

- links to open access Roman datasets,

- an open source model library implementing common Roman economics concepts that can be reused,

- an exhaustive bibliography of studies applying the approach,

- and it organises practical workshops to teach computational modelling to scholars in Roman studies at different stages of their careers.

All of these resources are used by the project team in a range of case studies that illustrate how the method can make important contributions to Roman economy studies, exploring phenomena such as Roman amphora reuse, Roman economic integration and ceramic product preference.
RECENT POSTS

Welcome to Project MERCURY-SIMREC

AFFILIATED WITH:

The Oxford Roman Economy Project

\section{PROJECT FUNDED BY:}

Project SIMREC has received funding from the European Union's Horizon 2020 research and innovation programme under grant agreement No 791948.

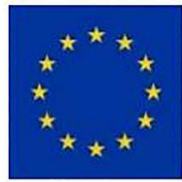

\section{LEVERH U L M $T R \cup S T$}

FIGURE 4. Project MERCURY-SIMREC home page.

archaeology can perhaps finally fulfill its potential as a core nexus in the present and future of our discipline.

\section{NOTES}

1. Main contributors to ODATE: Shawn Graham, Neha Gupta, Jolene Smith, Andreas Angourakis, Michael Carter, and Beth Compton.

2. PM team members: Tom Brughmans, Chico Camargo, Jacco van der Duin, Joris Kanters, Laura Paredes Fortuny, Yayoi Teramoto Kimura, and Andrew Wilson.

3. PH editorial board: Maria José Afanador-Llach, James Baker, Adam Crymble, Victor Gayol, Jennifer Isasi, François Dominic Laramée, Zoe LeBlanc, Matthew Lincoln, José Antonio Motilla, Joshua G. Ortiz Baco, Sofia Papastamkou, Jessica Parr, Marie Puren, Riva Quiroga, Antonio Rojas Castro, Anna-Maria Sichani, Anandi Silva Knuppel, Amanda Visconti, and Brandon Walsh.

\section{REFERENCES CITED}

\section{COMSES Network}

2019 OpenABM Model Library. Electronic document, https://www.comses. net/, accessed November 26, 2019.
Dallas, Costis

2015 Curating Archaeological Knowledge in the Digital Continuum: From Practice to Infrastructure. Open Archaeology 1:176-207.

Digital Antiquity

2019 The Digital Archaeological Record (tDAR). Electronic document, https:// core.tdar.org, accessed November 26, 2019

Institute for Digital Archaeology Method \& Practice Knowledge Base 2019 Digital Archaeology Knowledge Base. Electronic document, http:// digitalarchaeology.msu.edu/kb/, accessed November 26, 2019.

Perry, Sara, and James S. Taylor

2018 Theorising the Digital: ACall to Action for the Archaeological Community. In Oceans of Data: Proceedings of the 44th Conference on Computer Applications and Quantitative Methods in Archaeology, edited by Mieko Matsumoto and Espen Uleberg, pp. 11-22. Archaeopress, Oxford. Romanowska, lza, and Lennart Linde

2017 Literature on Agent-Based Models in Archaeology. Electronic document, https://github.com/ArchoLen/The-ABM-in-ArchaeologyBibliography, accessed November 26, 2019.

\section{AUTHOR INFORMATION}

Dries Daems — Department of Archaeology, University of Leuven, Blijde-Inkomststraat 21-, 3000 Leuven, Belgium (dries.daems@kuleuven.be) 